\title{
ShakeAlert-An Earthquake Early Warning System for the United States West Coast
}

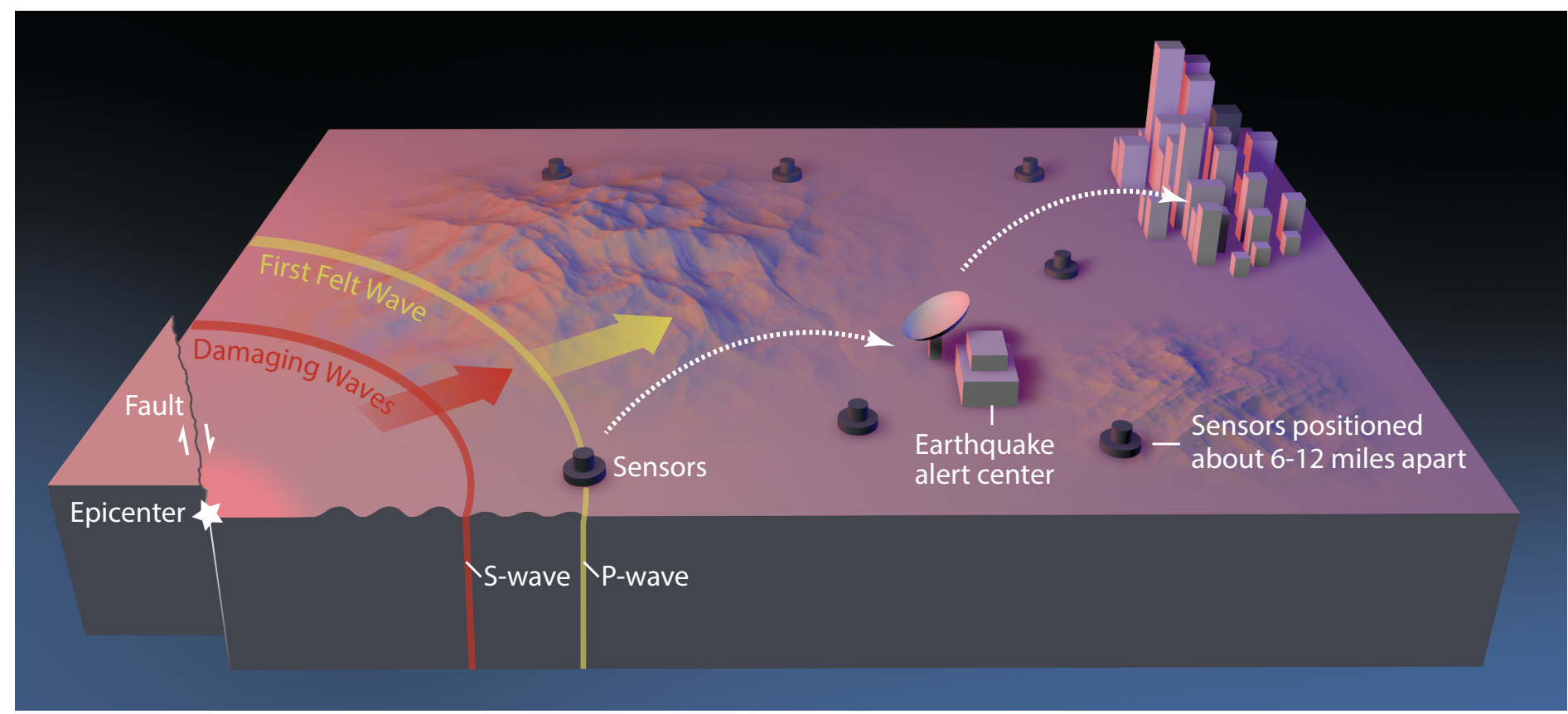

Earthquake early warning systems like ShakeAlert work because the warning message can be transmitted almost instantaneously, while shaking waves from the earthquake travel through the Earth at speeds of a few miles per second. When an earthquake occurs, seismic waves -including compressional (P) waves, transverse (S) waves, and surface waves - radiate outward from the epicenter. The faster but weaker $P$ waves trip nearby sensors, causing alert signals to be sent out, giving people and automated electronic systems some time (seconds to minutes) to take protective actions before the arrival of the slower but stronger S waves and surface waves. Computers and mobile phones receiving the alert message can calculate the expected arrival time and intensity of shaking at your location. USGS image created by Erin Burkett (USGS) and Jeff Goertzen (Orange County Register).

\begin{abstract}
Tarthquake early warning systems use earthquake science and the technology of monitoring systems to alert devices and people when shaking waves generated by an earthquake are expected to arrive at their location. The seconds to minutes of advance warning can allow people and systems to take actions to protect life and property from destructive shaking. The U.S. Geological Survey (USGS), in collaboration with several partners, has been working to develop an early warning system for the United States. ShakeAlert, a system currently under development, is designed to cover the West Coast States of California, Oregon, and Washington.
\end{abstract}

Earthquakes pose a serious risk to our Nation. According to the Federal Emergency Management Agency (FEMA), 77 percent of that risk, or an average annual loss of $\$ 4.1$ billion, is concentrated on the West Coast in California, Oregon, and Washington (Federal Emergency Management Agency, 2008). Growing urbanization and increasing reliance on complex infrastructure for power, water, telecommunication, and transportation magnify that risk. An earthquake early warning system that can rapidly detect earthquakes and send alerts could prompt actions to protect life and property before strong shaking arrives. Development of such a system is a critical step toward offsetting physical risks, improving public understanding of earthquake hazards, and reducing fear of the unknown and unpredictable nature of earthquakes.

\section{How Do Earthquakes and Early Warning Systems Work?}

An earthquake occurs when a fault in the Earth's crust slips suddenly and the two sides move relative to one another. The rupture begins at one point on the fault and rapidly extends along some distance of the fault, like a lengthening crack in a car windshield. As the rupture travels along the fault, the sudden movement of the two sides of the fault generates seismic (shaking) waves that radiate outward through the Earth-much like ripples from a stone dropped in water. It is these waves that cause the ground shaking you can feel and the damage and destruction during earthquakes.

Although no one can predict earthquakes, the technology exists to provide warning to surrounding communities once a quake begins. This is done by an 


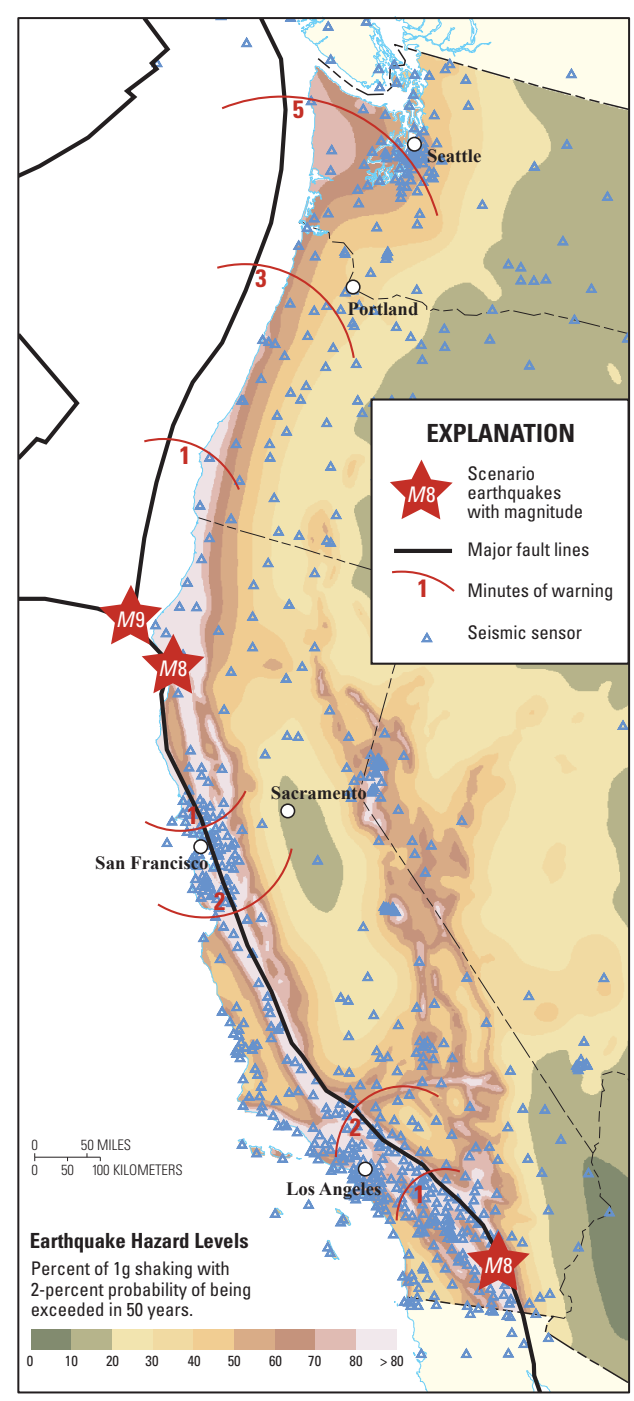

Map of the United States West Coast showing the amount of advance warning time that might be available from a system like ShakeAlert for several plausible future earthquake scenarios. Those scenarios include magnitude $8(M 8)$ quakes on the San Andreas Fault with epicenters in northern and southern California and an M9 quake on the Cascadia Subduction Zone with an epicenter offshore of northernmost California. Major population centers could have as much as several minutes warning before shaking waves from those quakes arrived. The map also shows the regional variation in the level of earthquake hazard in terms of the intensity of shaking (as a percentage of $g$, the acceleration of gravity) having at least a 2-percent probability of being exceeded in a 50-year period (from 2014 USGS hazard map). The network of seismic (earthquake) sensors is more concentrated near major faults and population centers. Illustration modified from Allen (2013). earthquake early warning system, which rapidly detects seismic waves as an earthquake happens, calculates the maximum expected shaking, and sends alerts to electronic devices and people before damaging waves arrive. Early warning is possible because information can be sent through communication systems virtually instantaneously, whereas seismic waves travel through the shallow Earth at speeds ranging from 0.5 to 3 miles per second. This means that the shaking can take seconds or even minutes to travel from where the earthquake occurred to where you are.

Thus it is possible for automated systems or even your personal electronic devices, such as smartphones, to receive an alert before destructive shaking arrives. The USGS, in collaboration with State agencies, universities, and

\section{How Warning Can Increase Safety and Prevent Damage}

Even a few seconds of warning can enable actions that protect people and property. In the time between receipt of an alert and arrival of damaging shaking, the following actions can be taken:

\section{Human Responses}

- Public-Citizens, including schoolchildren, Drop, Cover, and Hold On; turn off stoves; safely stop vehicles

- Businesses-Personnel move to safe locations

- Medical services-Surgeons, dentists, and others stop delicate procedures.

- Emergency responders-0pen firehouse doors, personnel prepare and prioritize response decisions

\section{Automated Responses}

- Businesses-Open elevator doors, shut down production lines, secure chemicals, place sensitive equipment in a safe mode

- Transportation-Automatically slow or stop trains to prevent derailment

- Power infrastructure-Protect power stations and grid facilities from strong shaking private companies, has been developing and testing ShakeAlert, an early warning system for the West Coast of the United States.

\section{How Does ShakeAlert Work?}

ShakeAlert has been in development since 2006 and began sending alerts to test users in California in January 2012 (see http://www.shakealert.org). The system detects earthquakes using our Nation's existing infrastructure for earthquake monitoring. The California Integrated Seismic Network (CISN) is a network of more than 400 high-quality ground motion sensors operated by the USGS in partnership with the State of California, California Institute of Technology, and University of California, Berkeley. The Pacific Northwest Seismic Network (PNSN) is a collaboration of the USGS, University of Washington, and University of Oregon. These regional networks are part of the Advanced National Seismic System (ANSS). ShakeAlert leverages and extends these networks' current research and post-earthquake response functions. When fully operational, ShakeAlert will be able to distribute alerts through all available distribution channels, including FEMA's Wireless Emergency Alerts (WEA) and Integrated Public Alert and Warning System (IPAWS), smartphone apps, social media providers, and other electronic alert technologies as they develop.

Test users of ShakeAlert currently receive alerts through a computer application with both audible and visual alert features. When ShakeAlert detects an earthquake, a map pops up on the user's screen to show the location of the earthquake epicenter (the point on the surface directly above the quake's starting point) and of waves moving toward the user; also shown is the time remaining until waves will reach the user's location and an estimate of the intensity of shaking. An alert sound alternates with a voice that counts down to the arrival time of seismic waves and announces the expected intensity.

\section{How Much Warning is Possible?}

An early warning system like ShakeAlert can provide seconds to minutes of warning before strong shak- ing arrives. The amount of warning time depends on the speed of the warning system and your distance from the epicenter. 
An effective system requires a dense network of sensors to ensure that there are enough of them near all possible earthquake sources. Such a dense network can reduce the area near the epicenter for which reliable warning is not possible because the earthquake source is too close for an alert to outpace the seismic waves. The farther a location is from the epicenter, the greater the amount of warning time. To maximize warning time, the system must minimize delays in data processing, communication, and delivery of alerts.

\section{Major Components of an Early Warning System}

The ability to send adequate warning before shaking arrives requires the following:

- A network of sensors that are densely spaced and close to faults

\section{Why ShakeAlert Emphasizes Intensity, not Magnitude}

The shaking you feel is described by earthquake intensity rather than magnitude. High intensities are what cause damage in earthquakes.

\section{Intensity}

- Represents the level of shaking caused by earthquake waves at a particular location

- Depends on magnitude + distance + local geology

- Varies from place to place in a single earthquake

\section{Magnitude}

- Is one number representing the amount of energy released in an earthquake

- Depends on the size (surface area) of fault rupture

ShakeMaps (Wald and others, 2003) rapidly show the distribution of intensity after an earthquake (https://earthquake.usgs.gov/earthquakes/shakemap/).

You can also report the ground shaking you experienced to help create Did You Feel It? intensity maps (https://earthquake.usgs.gov/ earthquakes/dyfi/).
- Quick and robust telecommunication from sensors to data processing centers

- Computer algorithms to quickly estimate an earthquake's location, magnitude, and fault rupture length, and to map resulting intensity

- Quick and reliable mass notifications

- End users educated in how to use the alerts

\section{Future Developments}

During its testing phase, ShakeAlert has detected thousands of earthquakes, including two that caused damage. The system began sending alerts within 4 seconds of the beginning of the M5.1 La Habra earthquake on March 28, 2014. ShakeAlert also sent alerts for the M6.0 South Napa earthquake on August 24, 2014, giving test users in Berkeley,

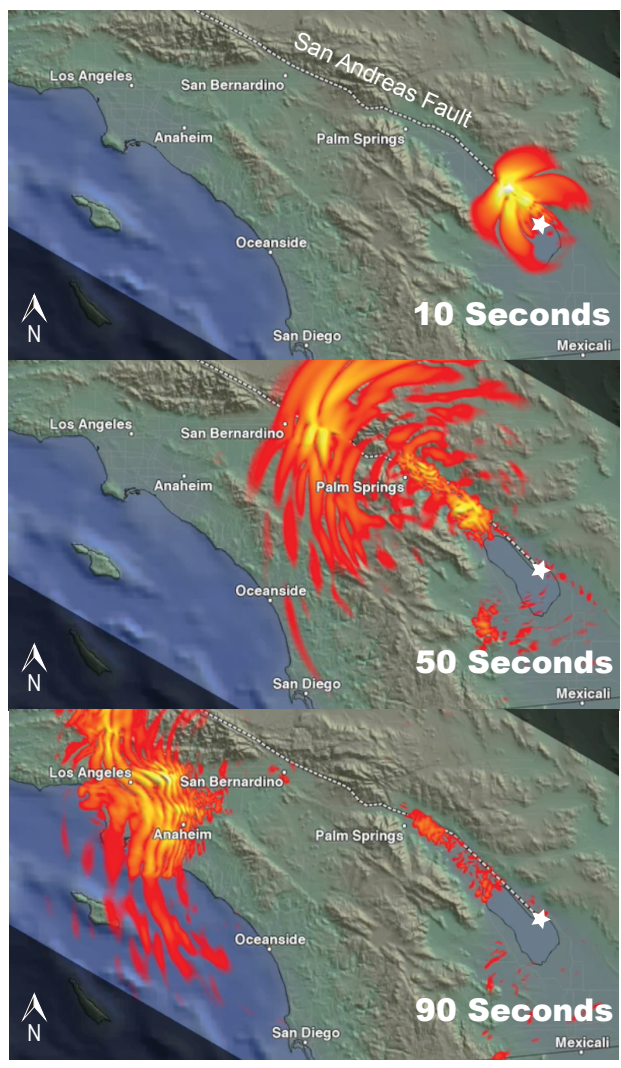

Diagrammatic maps showing northwestward spreading of ground shaking (red and yellow) generated by the $M 7.8$ ShakeOut scenario earthquake centered in the Imperial Valley of southern California. The times shown are times after the start of the earthquake rupture at the epicenter (white star). This scenario was part of a comprehensive earthquake exercise conducted in the State of California in 2008 (Perry and others, 2008).
California, 5 seconds of warning before shaking arrived.

Ongoing improvements to the sensor networks and data processing centers allowed the ShakeAlert system to advance from a "demonstration" to a "production prototype" phase in February 2016, allowing selected users to develop pilot implementations that take protective actions. USGS has published an implementation plan spelling out the steps needed to complete the system and begin issuing public alerts (Given and others, 2014). Public alerts and large-scale automatic implementation require additional development and further testing to make ShakeAlert sufficiently reliable (see sidebar "How Warning Can Increase Safety and Prevent Damage"), as well as end-user education on how to understand and use alerts.

The successful completion of the system will require the coordinated

\section{Will the West Coast have an Early Warning System Before or After the Next Big Quake?}

Most countries with early warning systems built them after a devastating earthquake.

Japan invested $\$ 600$ million in such a system after the 1995 Kobe earthquake killed 6,400 people. Today, Japan's system allows every citizen to receive advance alert of earthquake ground shaking from the Japan Meteorological Agency. Thanks to this system, no trains derailed in the 2011 magnitude 9.0 Tohoku earthquake, and according to a poll in Japan, 90 percent of the citizens think the system is worth the investment (Fujinawa and Noda, 2013).

Other countries that built systems after devastating earthquakes include

- China (after the 2008 Wenchuan earthquake killed 87,587 people)

- Taiwan (after the 1999 Chi Chi earthquake killed 2,415)

- Turkey (after the 1999 Izmit earthquake killed 17,127)

- Mexico (after the 1985 Mexico City earthquake killed 10,153) 
efforts of government agencies at all levels, private companies, and the public. California has committed to developing earthquake early warning statewide, and companies are beginning to develop products to use and distribute the alerts.

The ongoing work of USGS scientists, together with partner organizations, on earthquake early warning systems is only part of the National Earthquake Hazard Reduction Program's efforts to safeguard lives and property from the future quakes that are certain to strike along the West Coast and other areas of the United States.

\section{References}

Allen, R., 2013, Seismic hazards; seconds count: Nature, v. 502, no. 7469, accessed 2014 at http://www.nature. com/news/seismic-hazards-secondscount-1.13838.

Federal Emergency Management Agency, 2008, FEMA 366; HAZUS-MH estimated annualized earthquake losses for the United States: Federal Emergency Management Agency, accessed 2014 at https://www.fema.gov/media-library/ assets/documents/13293?id=3265.

Fujinawa, Y., and Noda, Y., 2013, Japan's earthquake early warning system on 11 March 2011-Performance, shortcomings, and changes: Earthquake Spectra, v. 29, no. S1, p. S341-S368, http:// dx.doi.org/10.1193/1.4000127.

Given, D.D., Cochran, E.S., Heaton, T., Hauksson, E., Allen, R., Hellweg, P., Vidale, J., and Bodin, P., 2014, Technical implementation plan for the ShakeAlert production system-An earthquake early warning system for the West Coast of the United States: U.S. Geological Survey Open-File Report 2014-1097, 25 p., https://doi. org/10.3133/ofr20141097.

Perry, S., Cox, D., Jones, L., Bernknopf, R., Goltz, J., Hudnut, K., Mileti, D., Ponti, D., Porter, K., Reichle, M., Seligson, H., Shoaf, K., Treiman, J., and Wein, A., 2008, The ShakeOut earthquake scenario-A story that southern Californians are writing: U.S. Geological Survey Circular 1324, 16 p. [Also available at https://pubs.usgs.gov/ circ/1324/.]

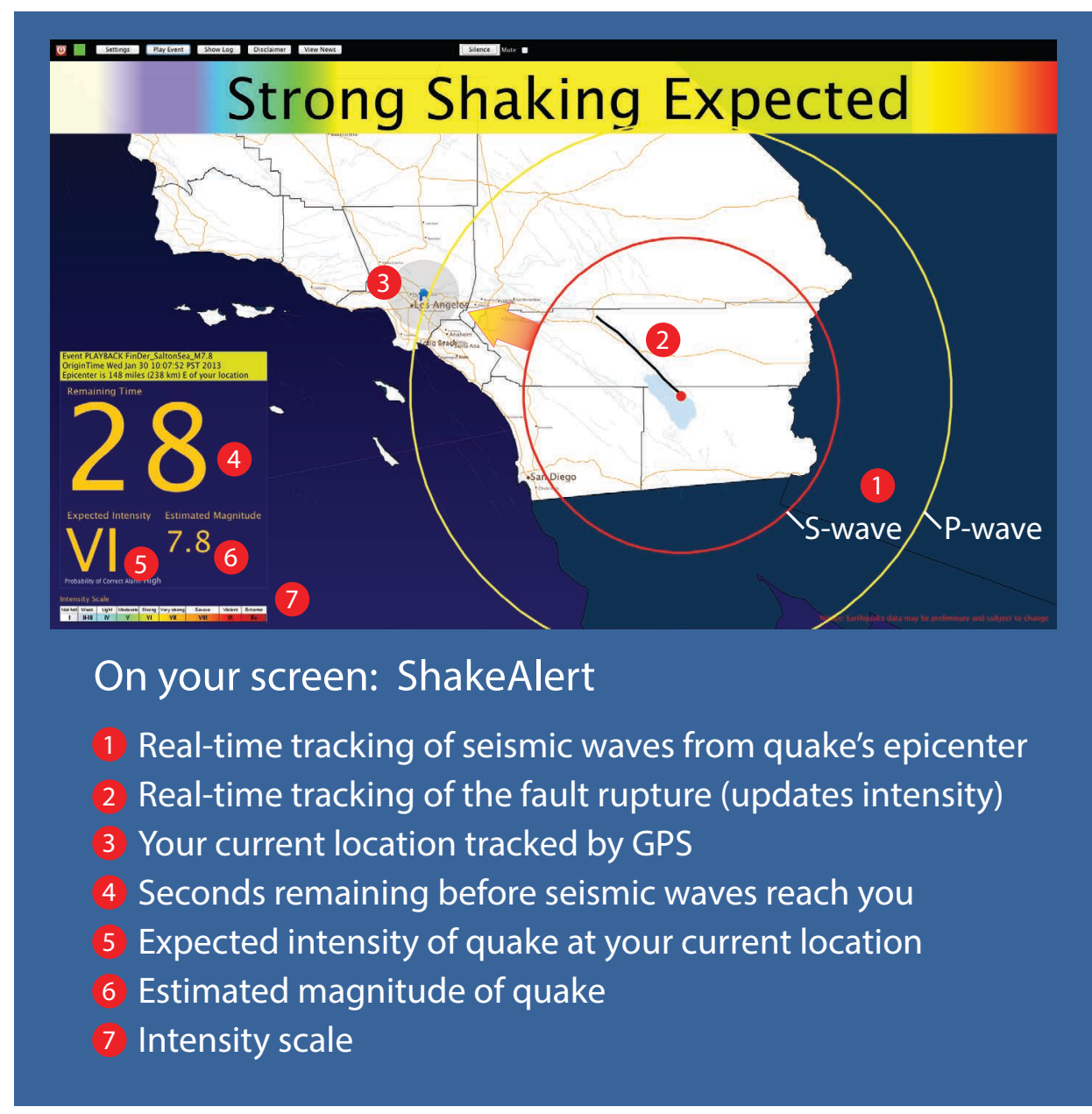

A user of the current ShakeAlert user display receives a message like this on the screen of his or her computer. The message alerts the user to how many seconds before the shaking waves arrive at their location and the expected intensity of shaking at that site. The shaking intensity follows the Modified Mercalli scale; an intensity of VI, as shown here, would mean the shaking is felt by everyone, people find it difficult to stand, and structures may suffer some damage. The warning message also displays a map with the location of the epicenter, the magnitude of the quake, and the current position of the $P$ and $S$ waves. In this example, the alert is for the ShakeOut scenario earthquake (Perry and others, 2008).

Wald, D., Wald, L., Worden, B., and Goltz, J., 2003, ShakeMap-A tool for earthquake response: U.S. Geological Survey Fact Sheet 087-03, 4 p., [Also available at https://pubs.usgs.gov/fs/ fs-087-03/.]

Erin R. Burkett, Douglas D. Given, and Lucile M. Jones

Edited by Peter H. Stauffer and Jessica Dyke

Layout by Vivian Nguyen

\section{COOPERATING ORGANIZATIONS}

California Geological Survey

California Institute of Technology

California Office of Emergency Services The Moore Foundation

Southern California Earthquake Center Swiss Federal Institute of Technology, Zürich University of California, Berkeley University of Oregon University of Washington
For more information contact: U.S. Geological Survey

Earthquake Hazards Program Earthquake Early Warning https://earthquake.usgs.gov/research/ earlywarning/

or

Robert de Groot rdegroot@usgs.gov

This Fact Sheet and any updates to it are available online at: https://pubs.usgs.gov/fs/2014/3083/
ISSN 2327-6916 (print) ISSN 2327-6932 (online) https://doi.org/10.3133/fs20143083 